\title{
Arte Rupestre, Paisaje y Tensión Social: Un Caso de Estudio en Córdoba, Argentina.
}

\author{
Rock Art, Landscape and Social Tension: A Case Study from \\ Córdoba, Argentina.
}

\author{
Sebastián Pastor ${ }^{1}$
}

\begin{abstract}
Resumen
Se presenta un análisis del arte rupestre en las serranias noroccidentales de Córdoba, en la región central de Argentina. Se atiende a las caracteristicas del repertorio iconográfico (tipos de motivos, temas, cánones de diseño) y a variables contextuales como la asociación con los recursos, selección de los soportes, visibilidad y otras actividades relacionadas con la producción y observación de las imágenes. A partir de dicha información se evaluan aspectos de las antiguas construcciones paisajisticas, territoriales y de los vinculos sociales. En tal sentido, se consideran las afinidades y diferencias entre las modalidades estilisticas identificadas en diversos entornos, teniendo en cuenta su vinculación con la tensión social, la negociación de las relaciones intergrupales y las condiciones de acceso territorial.

Palabras clave: Sierras de Córdoba, Período Prehispánico Tardío, Arte Rupestre, Construcción del Paisaje, Tensión Social.
\end{abstract}

\begin{abstract}
An analysis of rock art in northwestern hills of Córdoba (central region of Argentina) is presented. The study takes into account the characteristics of the iconographic repertory (motifs types, themes and design canons), as well as contextual variables like association with resources, rock selection, visibility and other activities related to the production and observation of images. With this information we then evaluate the social construction of ancient landscapes, territories and social ties. We then consider the affinities and differences between the stylistic modalities identified in several environments and their relation to social tension, inter-groups negotiations and territorial access conditions.
\end{abstract}

Key words: Córdoba Hills, Late Prehispanic Period, Rock Art, Landscape Construction, Social Tension.

CONICET. Área de Arqueología y Etnohistoria del Centro de Estudios Históricos "Prof. Carlos S. A. Segreti”. M. C. del Corro 308 (5000), Córdoba, Argentina. Correo-e: pastorvcp@yahoo.com.ar Recibido: marzo 2012 Revisado: mayo 2012 Aceptado: julio 2012 


\section{INTRODUCCIÓN}

En la investigación arqueológica actual se reconoce la importancia de los estudios de arte rupestre como un área privilegiada para entender la construcción y reproducción de la realidad social, en tanto elemento material activo en los procesos históricos contingentes (Criado 1999, Fiore 2009, Gallardo 2001). A partir de un profundo enraizamiento en la trama cultural y la acción social, y por su distribución diferencial en el espacio, el arte rupestre es capaz de imbuir al entorno con una cierta carga semántica, que resulta particular de cada contexto geográfico y momento histórico (Troncoso 2005). En tal sentido, porta y transmite significaciones que posibilitan el mantenimiento y reproducción de la memoria grupal, o en ocasiones, también la transformación o subversión de las pautas de relación entre los agentes y colectivos sociales.

En cuanto a las formas de concebir, organizar y habitar el paisaje, tales pautas pueden favorecer la inclusión o por el contrario la exclusión a diferentes escalas espaciales y sociales (Piazzini 2006), denotando lógicas y niveles de tensión asociados a los procesos de interacción grupal. Dichos mecanismos de inclusión y exclusión, así como los conflictos y negociaciones asociados, integran los tópicos y problemáticas abordados en esta contribución.

Dentro de la región de las Sierras Centrales de Argentina, el extenso valle de Traslasierra, al occidente de la provincia de Córdoba, conserva numerosas expresiones de arte rupestre (Murra 1965, Pastor 2009, 2010; Recalde 2006, 2009; Recalde y Pastor 2011, 2012; Romero y Uanini 1978; Romero et al. 1973). Otras áreas de concentración corresponden a las sierras del norte de Córdoba (Gardner, 1931; Urquiza, 2011), el sur de las sierras de Comechingones (Rocchietti 2000) y las sierras de San Luis (Consens 1986), aunque también existen vastas extensiones sin manifestaciones de este tipo o con sitios puntuales dispersos en amplios espacios.

En esta oportunidad, dentro del valle de Traslasierra, tomaremos una microrregión específica que incluye a las sierras noroccidentales de Córdoba (Figura 1). La misma contiene el mayor número de sitios con arte rupestre, el cual se caracteriza por una marcada variabilidad que permite distinguir modalidades estilísticas con distribuciones acotadas por áreas o bien, en otros casos, ocupando los mismos entornos pero estableciendo términos de relación que, según planteamos, acusan determinados niveles de tensión social. Estas condiciones posicionan al arte rupestre como una materialidad privilegiada para identificar formas más o menos inclusivas en la ocupación 
del espacio, implicando lógicas y criterios diferenciales en la construcción del paisaje y la territorialidad.

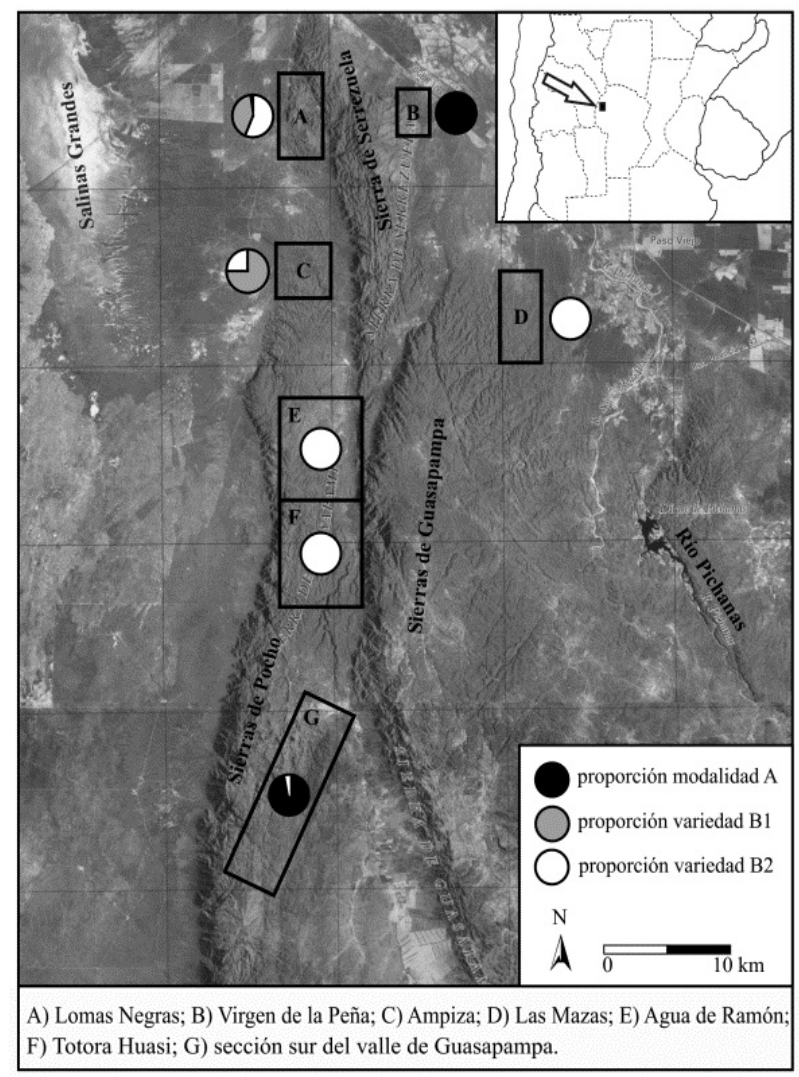

Figura 1: Áreas investigadas en las serranías noroccidentales de Córdoba (Argentina).

Figure 1: Studied areas in north-western Córdoba hills (Argentina).

\section{BREVE CARACTERIZACIÓN DEL CASO DE ESTUdIO}

La microrregión de las sierras noroccidentales de Córdoba (Pocho, Guasapampa y Serrezuela; Figura 1) incluye cordones serranos de baja altitud (hasta $900 \mathrm{msnm}$ ) así como las áreas pedemontanas circundantes. Entre las sierras de Pocho y Guasapampa se extiende un pequeño valle denominado Guasapampa, con una longitud aproximada de $60 \mathrm{~km}$ y una marcada estrechez, con menos de $3 \mathrm{~km}$ de ancho y, en algunos puntos, apenas unas decenas de metros. El ambiente se distingue por el clima cálido y seco, con una acentuada escasez del recurso hídrico. Exceptuando algunos cursos de 
agua intermitentes, como el río Guasapampa en sus tramos iniciales, casi todos los cauces permanecen secos durante todo el ańo y únicamente se activan por algunas horas o días después de las lluvias torrenciales de verano. El entorno se distingue por su riqueza forestal. El bosque transicional entre el Chaco Serrano y el Chaco Seco (Karlin et al., 1994) cuenta con especies con frutos comestibles, como los algarrobos (Prosopis spp.), chañar (Geoffroea decorticans), mistol (Zizyphus mistol) y cardón (Stetsonia coryne).

Los estudios dan cuenta de una ocupación poco intensa y aún esporádica de este paisaje durante el Holoceno Temprano, Medio y comienzos del Tardío ( $c$ a. 8500-2000 AP), que se tradujo en una baja densidad de sitios y hallazgos aislados (Pastor 2010, Recalde y Pastor 2012). Este panorama se habría revertido con posterioridad a $c a .1500 \mathrm{AP}$, con la multiplicación del número y diversidad de contextos arqueológicos (Pastor 2010, Recalde 2008-09, 2009). De todos modos, no se registran los típicos asentamientos residenciales a cielo abierto que distinguen a los paisajes agrícolas prehispánicos (Berberián 1984, Pastor 2007-08), sino sitios de uso transitorio y estacional ligados a la explotación del medio forestal (Pastor 2010, Recalde 2008-09). Únicamente a partir de este período los paisajes áridos habrían sido incorporados en forma efectiva a los circuitos de movilidad estacional. A través de los mismos, se articulaban las áreas agrícolas en los valles fértiles del oriente (con disponibilidad permanente de agua) con microambientes serranos adversos para los cultivos, pero localizados a corta distancia y dotados de recursos complementarios para una economía mixta que combinaba la agricultura con la caza-recolección (Pastor 2005, Pastor y Medina 2005, Recalde 2008-09).

\section{Arte rupestre de las sierras noroccidentales de Córdoba}

La identificación de numerosos sitios arqueológicos con arte rupestre fue el resultado de un programa intensivo de prospecciones, comprendiendo varias decenas de kilómetros cuadrados, distribuidos en sectores representativos de la diversidad paisajística y ambiental que distingue a la microrregión (Pastor 2010, Recalde 2009, Recalde y Pastor 2011, 2012). Los diferentes paneles fueron registrados teniendo en cuenta las formas y tamaño de los motivos, su posición en la roca soporte, las técnicas de ejecución, superposiciones y diferencias de pátinas en el caso de los grabados, y de tonalidades en las pinturas. Asimismo, se tuvieron en cuenta las características de los emplazamientos, la asociación con otros materiales arqueológicos, con los recursos naturales y rasgos del paisaje, las condiciones de visibilidad 
de las imágenes y de los soportes que las contienen, el dominio visual desde los sitios y la intervisibilidad entre paneles o geoformas conteniendo paneles con arte rupestre. Sólo en la sección sur del valle de Guasapampa (Recalde 2008-09, 2009), y en uno de los sitios del área de Virgen de la Peña (Figura 1), se conservan depósitos estratificados al pie de los paneles que permitieron practicar excavaciones y acceder a un panorama más amplio de las actividades llevadas a cabo, así como a estimaciones cronológicas basadas en las características ergológicas y en fechados radiocarbónicos.

Los sitios se distribuyen sobre ambas vertientes de las sierras de Pocho, Guasapampa y Serrezuela, ocupando con preferencia los entornos pedemontanos y sectores del valle de Guasapampa (Pastor 2010, Recalde 2009, Recalde y Pastor 2011, 2012). Sin embargo, la concentración más significativa sólo abarca un pequeño sector del piedemonte oriental de las sierras de Pocho $\left(20 \mathrm{~km}^{2}\right)$, en el sur del valle de Guasapampa, donde se documentaron 36 sitios (Recalde 2009), aunque existió un mayor número en el pasado (Figura 1) ${ }^{1}$. El patrón concentrado distingue a este espacio particular y contrasta con el resto de la microrregión, donde los sitios muestran una distribución dispersa, existiendo además amplios sectores sin tales expresiones.

Casi todos los sitios del sur de Guasapampa (Tabla 1) pertenecen a una modalidad estilistica distintiva, que denominaremos A, y que se define por los tipos de motivos y asociaciones temáticas, las técnicas de producción de las imágenes y las clases de soportes seleccionados (Recalde 2009)². Este arte rupestre se diferencia por una marcada diversidad de motivos, especialmente zoomorfos, pero con un amplio predominio de los camélidos, que son las imágenes que componen la mayoría de los temas (Recalde y Pastor 2012). En más de un $95 \%$ de los motivos la técnica de ejecución corresponde a las pinturas, en tanto que los soportes elegidos se localizan dentro de abrigos rocosos de uso doméstico y estacional estival (Recalde 2008-09). Esta posición confiere una visibilidad generalmente baja a las imágenes, que sólo pueden ser apreciadas por aquellos que conocen la ubicación de los refugios (normalmente poco diferenciada en el contexto litológico y vegetacional) e ingresan al interior de los mismos (Tabla 2). Fuera de la sección sur de Guasapampa se registran manifestaciones de este tipo, en forma dispersa, en el área de Virgen de la Peńa, en el oriente de Serrezuela (Figura 1; Tabla 1).

Los contextos estratificados y las dataciones radiocarbónicas vinculadas a paneles de esta modalidad estilística sugieren una cronología prehispánica tardía (ca. 1400-400 AP), con persistencias durante el período 
colonial temprano, evidenciadas por la incorporación de équidos en algunos sitios (Recalde 2009, 2012).

\begin{tabular}{|c|c|c|c|}
\hline Área & Modalidad A & Variedad B1 & Variedad B2 \\
\hline Lomas Negras & $\begin{array}{c}1 \\
(2.56 \%) \\
\end{array}$ & $\begin{array}{c}16 \\
(41.03 \%) \\
\end{array}$ & $\begin{array}{c}22 \\
(56.41 \%) \\
\end{array}$ \\
\hline Virgen de la Peña & $\begin{array}{c}7 \\
(100 \%)\end{array}$ & - & - \\
\hline Las Mazas & - & - & $\begin{array}{c}8 \\
(100 \%) \\
\end{array}$ \\
\hline Ampiza & - & $\begin{array}{c}6 \\
(75 \%) \\
\end{array}$ & $\begin{array}{c}2 \\
(25 \%) \\
\end{array}$ \\
\hline Agua de Ramón & - & - & $\begin{array}{c}6 \\
(100 \%)\end{array}$ \\
\hline Totora Huasi & - & - & $\begin{array}{c}7 \\
(100 \%) \\
\end{array}$ \\
\hline Sur Guasapampa & $\begin{array}{c}64 \\
(96.97 \%) \\
\end{array}$ & - & $\begin{array}{c}2 \\
(3.03 \%) \\
\end{array}$ \\
\hline Total de paneles & 72 & 22 & 47 \\
\hline
\end{tabular}

Tabla 1: Cantidad de paneles y frecuencia de representación por área.

Table 1: Number of panels and representation frequency by area.

En oposición a esta modalidad estilística, en la sección norte del valle de Guasapampa (áreas de Totora Huasi, Agua de Ramón y Ampiza; Figura 1) se conserva un arte rupestre de características contrastantes, asignado a otra modalidad que llamaremos B (Tabla 1; Pastor 2010, Recalde y Pastor 2012). Además de su distribución más o menos dispersa, los sitios se diferencian por su emplazamiento en bloques a cielo abierto, paredones y aleros, en posiciones que no impiden un acceso visual amplio e irrestricto a las figuras, a veces desde cierta distancia (entre 10 y $50 \mathrm{~m}$ ). La asociación con aguadas estacionales (los hitos geográficos más significativos) es consistente en todos los casos, mientras que los indicadores de actividad son diversos. En ocasiones, estos indicadores están completamente ausentes, sugiriendo que la ejecución y observación de las imágenes fueron las principales tareas llevadas a cabo, o al menos, que eventuales prácticas de procesamiento culinario y consumo no habrían sido recurrentes en dichos lugares. En otros casos sí se presentan vestigios arqueológicos asociados (útiles de molienda, restos líticos y cerámicos) que indican actividades de procesamiento y consumo en diversas escalas de participación, que varían entre la doméstica (grupos con un mínimo nivel de inclusión) y la comunitaria (abarcando varias decenas de individuos; Pastor, 2009, 2010). Las técnicas de ejecución comprenden diferentes formas de grabado y excluyen casi por completo a las pinturas. A 
diferencia de la modalidad A, los temas conformados en base a las figuras de camélidos (asociados entre ellos y/o con otros motivos zoomorfos como lagartos, rheidos o cánidos, así como antropomorfos y no figurativos) no son abrumadoramente mayoritarios. Numerosos paneles integran únicamente a motivos no figurativos, mientras que en otros sobresalen los antropomorfos provistos de aditamentos como tocados y vestimentas (Figura 2 y Tabla 2; Recalde y Pastor 2012).

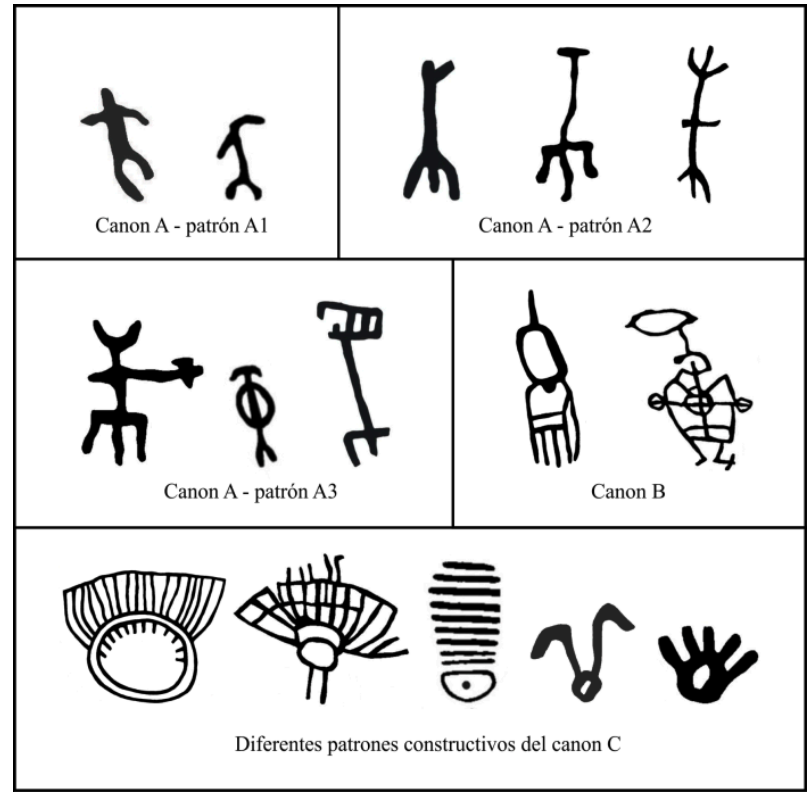

Figura 2: Cánones de diseño y patrones constructivos para la representación humana.

Figure 2: Design canons and constructive patterns for human depiction.

El empleo de técnicas de grabado y la ausencia de depósitos estratificados impiden por el momento contar con una cronología basada en dataciones absolutas. Sin embargo, los indicios permiten suponer una ejecución diacrónica en el caso de algunos paneles (diferencias de pátinas, superposiciones), pero con márgenes acotados al Período Prehispánico Tardío. En tal sentido, se destaca la coincidencia en los cánones de diseño y patrones constructivos (sensu Aschero 1996) con motivos del sur de Guasapampa, así como la presencia de restos cerámicos en todos los sitios que conservan residuos superficiales ${ }^{3}$. Algunos paneles puntuales dan cuenta de la perduración de las prácticas y sentidos ligados a la ejecución/observación de las imágenes durante el período colonial temprano, a través del agregado de motivos particulares como équidos. 
Las modalidades estilísticas A y B han sido relacionadas con construcciones diversas y aun contrapuestas de los paisajes sociales: la primera fue ligada a la significación de lugares puntuales de uso doméstico, y a la construcción de vínculos relativamente simétricos o equilibrados entre grupos mínimos de pertenencia, en medio de un paisaje social "abierto" (Recalde 2009). Por su parte, la modalidad B estaría asociada a la demarcación territorial, en relación a los hitos de mayor importancia económica y simbólica (las aguadas), con el establecimiento de articulaciones jerárquicas o asimétricas entre grupos más inclusivos, de nivel comunitario, y la construcción de un paisaje "cerrado" (Pastor 2010, Recalde y Pastor 2012).

\begin{tabular}{|l|c|c|c|}
\hline & Modalidad A & Variedad B1 & Variedad B2 \\
\hline Abrigo rocoso & $100 \%$ & $54,55 \%$ & $31,11 \%$ \\
Paredón & - & $45,45 \%$ & $68,89 \%$ \\
\hline $\begin{array}{l}\text { Sin evidencias de actividades } \\
\text { asociadas }\end{array}$ & $69,01 \%$ & $36,36 \%$ & $29,79 \%$ \\
$\begin{array}{l}\text { Procesamiento-consumo } \\
\text { (escala doméstica) }\end{array}$ & $29,58 \%$ & $45,45 \%$ & $14,89 \%$ \\
$\begin{array}{l}\text { Procesamiento-consumo } \\
\text { (escala extra-doméstica) }\end{array}$ & $1,41 \%$ & $18,18 \%$ & $55,32 \%$ \\
\hline Visibilidad alta (+ 7 m) & $5,71 \%$ & $45,45 \%$ & $73,33 \%$ \\
Visibilidad media (3/6 m) & $30 \%$ & $54,55 \%$ & $26,67 \%$ \\
Visibilidad baja (- 3 m) & $64,29 \%$ & - & - \\
\hline Grabado & $2,56 \%$ & $98,96 \%$ & $99,7 \%$ \\
Grabado-pintado & - & $0,52 \%$ & $0,3 \%$ \\
Pintado & $97,44 \%$ & $0,52 \%$ & - \\
\hline$\%$ antropomorfos cánones A-B & $1,15 \%$ & $3,65 \%$ & $6,95 \%$ \\
$\%$ antropomorfos canon C & $0,26 \%$ & $0,52 \%$ & $17,52 \%$ \\
$\%$ camélidos & $64,4 \%$ & $74,48 \%$ & $5,14 \%$ \\
$\%$ otros zoomorfos & $8,71 \%$ & $1,56 \%$ & $3,32 \%$ \\
$\%$ no figurativos & $25,48 \%$ & $19,79 \%$ & $67,07 \%$ \\
\hline
\end{tabular}

Tabla 2: Características intrínsecas y contextuales de los paneles. Table 2: Inherent and contextual characteristics of panels. 
Esta contribución se centra en la variabilidad interna del arte rupestre de la modalidad estilística $\mathrm{B}$, considerando un área de distribución más extensa que, además del norte del valle de Guasapampa, incluye el piedemonte nororiental de las sierras del mismo nombre y la vertiente occidental de las sierras de Serrezuela (Figura 1 y Tabla 1). Se plantea que dicha variabilidad comprende, básicamente, dos formas principales que comparten en gran medida el contexto de producción y uso, pero que tienen suficientes diferencias que justifican su separación, básicamente a nivel del repertorio iconográfico. Atendiendo a las variables analizadas planteamos que la relación entre ambas variedades, que denominaremos B1 y B2, estuvo caracterizada por una cierta cuota de tensión. Esta interacción tensa puede ser englobada bajo los principios que definimos como segregación, subordinación, supresión y exclusión.

\section{Segregación espacial: Áreas de Ampiza \\ Y LOMAS NEgRAS}

El modo más frecuente de manifestación de las diferencias contextuales entre las variedades B1 y B2 del arte rupestre de la modalidad estilística B, implicó la segregación espacial de los paneles de una y otra temática. Esto es, la no inclusión de los motivos y temas característicos de una variedad en los soportes ocupados por la otra. Esta característica es particularmente evidente en el área de Ampiza, en el extremo norte del valle de Guasapampa, y también en Lomas Negras, al occidente de Serrezuela (Figura 1).

En Ampiza los conjuntos mayoritarios son de la variedad B1 (Tabla 1), con temas y cánones de diseño similares a los de la modalidad estilística A del sur de Guasapampa. Esto es notorio, por ejemplo, en los sitios Ampiza 2 y Rodeo de Auti 8, con asociaciones de camélidos y antropomorfos del canon A (sensu Recalde y Pastor 2012, Figuras 2 y 3). Por su parte, la principal expresión de la variedad B2 se encuentra en un sitio diferente, comprendiendo al gran panel grabado de Ampiza 1 (Romero y Uanini 1978). Este último ocupa el frente de un alero en el punto exacto donde el cauce del río Guasapampa abandona el valle para internarse y desaparecer en la llanura. Además de su tamaño considerable (7 x 1,5 metros), este panel se destaca por el empleo de una técnica de ejecución infrecuente y relativamente costosa (surcos profundos). Asimismo, por las imágenes de grandes dimensiones, entre las que sobresalen antropomorfos del canon $\mathrm{C}$ (cabezas con tocados; sensu Pastor 2010; Figura 2), con ausencia total de motivos zoomorfos. 


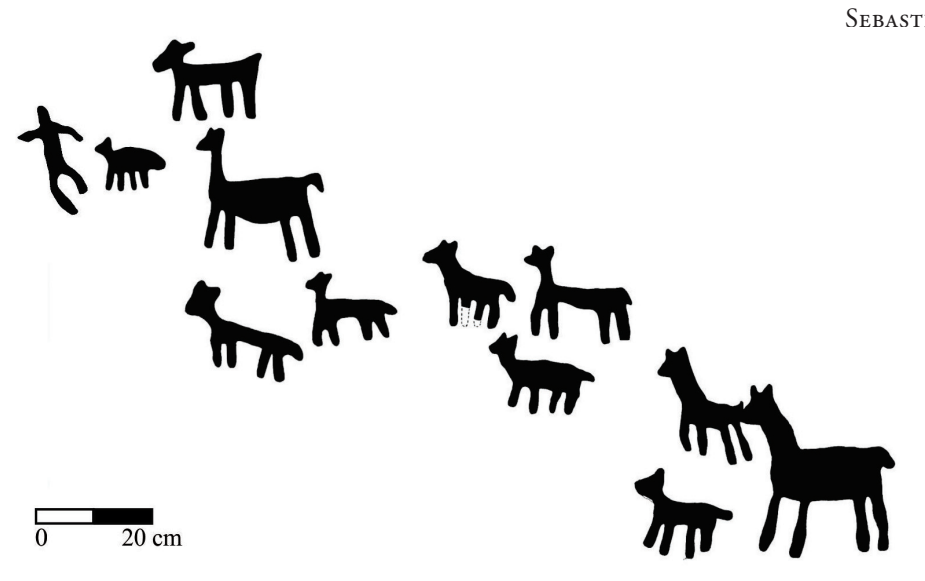

Figura 3: Panel grabado del sitio Rodeo de Auti 8 (área de Ampiza).

Figure 3: Engraved panel from Rodeo de Auti 8 site (area of Ampiza).

En el caso de Lomas Negras documentamos 15 paneles de la variedad B1 y 20 de la variedad B2. Este cómputo excluye a dos paneles con elementos combinados de ambas variedades (que serán tratados en la siguiente sección), así como a otros 21 pertenecientes a variedades minoritarias de la modalidad B o incluso a otras modalidades estilísticas, que serán analizados en otra oportunidad. La segregación de las dos variedades mayoritarias se observa en los diferentes sectores que integran el área. Por ejemplo en la subárea El Cajón se encuentran dos sitios con arte rupestre, en ambos casos relacionados con prácticas de molienda comunitaria: Cerco Quemado y El Cajón 1 (Pastor 2009, 2010). El primero excluye por completo a los motivos antropomorfos (su panel principal se distingue por el predominio de los camélidos y corresponde a la variedad B1), mientras que el segundo, excluye a las figuras zoomorfas excepto a las pisadas de felino. Sus paneles más significativos son asignados a la variedad $\mathrm{B} 2$, con una marcada recurrencia de los antropomorfos del canon C (Figura 2) y, en ocasiones, el empleo de la misma técnica de surcos profundos documentada en Ampiza 1 (Figura 4).

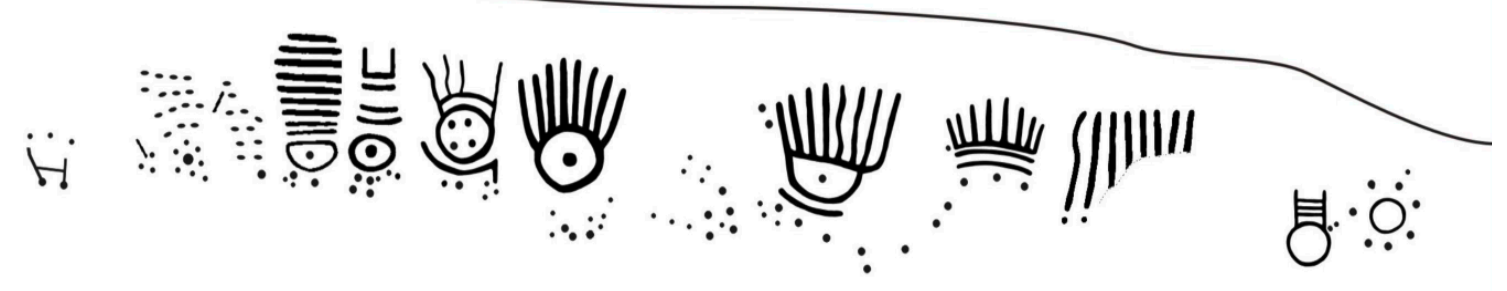

Figura 4: Panel n 7 del sitio El Cajón 1 (área de Lomas Negras).

Figure 4: Panel $n^{\circ} 7$ of El Cajón 1 site (area of Lomas Negras). 
En la subárea Sacha Cabra, a unos dos kilómetros hacia el norte, se ubica un sitio de molienda grupal junto a una aguada estacional (Pozo de la Sacha Cabra), con un panel con un único motivo correspondiente a una cabeza con tocado (variedad B2; Pastor 2010). A $300 \mathrm{~m}$ se localiza un conjunto de aleros con cuatro paneles de la variedad B1, con camélidos acompañados en dos ocasiones por antropomorfos del canon A. El mismo patrón se verifica a unos dos kilómetros al sur de El Cajón, en la subárea Cajones del Igno. El sitio más significativo, Cajones del Igno 1, presenta indicadores de molienda grupal en torno a una aguada y 10 paneles con arte rupestre distribuidos en un alero cercano y en dos oquedades de un mismo paredón rocoso. Las asociaciones presentes en estas oquedades corresponden a grupos de camélidos (variedad B1; Figura 5), en tanto que las existentes dentro del alero pertenecen mayoritariamente a la variedad B2. Además de este asentamiento principal registramos en la misma subárea otros cinco sitios pequeños con arte rupestre. También aquí se reconoce el principio de segregación, puesto que los paneles de tres de ellos (Cajones del Igno 2, 4 y 6) corresponden a la variedad B1, mientras que los del cuarto (Cajones del Igno 5), se atribuyen a la variedad B2. El quinto sitio, Cajones del Igno 3, representa una situación particular que analizaremos en la siguiente sección.

\section{$x+4$}

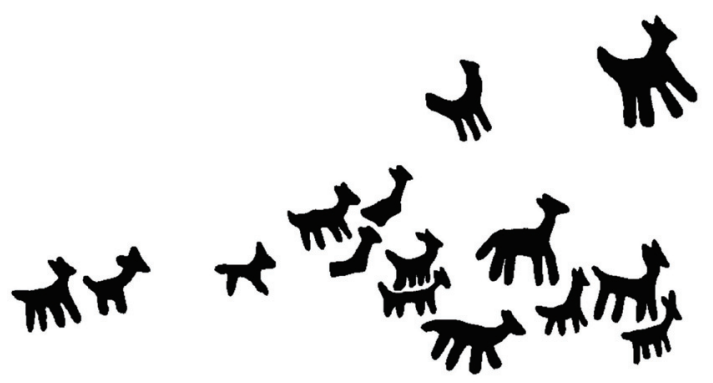

Figura 5: Panel $n^{\circ} 2$ del sitio Cajones del Igno 1 (área de Lomas Negras).

Figure 5: Panel no 2 of Cajones del Igno 1 site (area of Lomas Negras). 


\section{SUbORDINACIÓN/SUPRESIÓN: RÍO GUASAPAMPA 2, LOS PILONES 2 Y CAJONES DEL IGNO 3}

En las áreas de Ampiza y Lomas Negras existen tres paneles donde los motivos característicos de las variedades B1 y B2 coinciden en un mismo soporte. En estos casos relativamente infrecuentes (por el predominio del principio de segregación) se observan vinculaciones definidas por una cuota de tensión, que englobamos bajo los principios de subordinación y supresión, siempre favorables a los motivos B2.

Como vimos en el área de Ampiza las asociaciones B1 son mayoritarias. Los indicios sugieren que el panel grabado del sitio Río Guasapampa 2, en un paredón rocoso a orillas del cauce, pudo constituir originalmente otro ejemplo de esta variedad predominante. Sin embargo, las imágenes producidas por el raspado de la superficie fueron luego rayadas en forma desprolija, con el evidente propósito de destruir las figuras. La relativa eficacia de este procedimiento impide reconocer los motivos subyacentes, excepto un camélido que aún puede ser parcialmente identificado. A mayor altura, en un sector hasta entonces libre de grabados, se ejecutó un tema que presenta el mismo nivel de pátina que el rayado que anuló a la asociación original. Los nuevos motivos son tres antropomorfos alineados del canon B, con indicación de vestimentas y tocados (sensu Recalde y Pastor 2012; Figura 6). Este caso de destrucción e imposición de un nuevo tema es enmarcado dentro del principio de supresión.
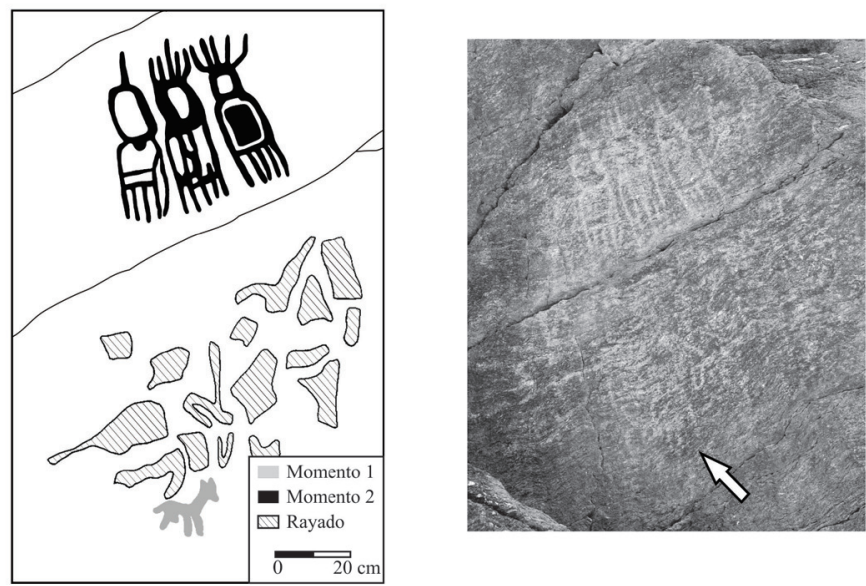

Figura 6: Panel grabado del sitio Rio Guasapampa 2 (área de Ampiza). Se aprecia la supresión de un tema presumiblemente B1 y la imposición de uno B2.

Figure 6: Engraved panel of Rio Guasapampa 2 site (area of Ampiza). The suppression of a predictable B1 theme and the imposition of a B2 theme are observed. 
Una situación similar se registra en el panel principal $\left(n^{\circ} 1\right)$ del sitio Los Pilones 2, en el área de Lomas Negras. Dicho panel ocupa el frente de un alero en la cabecera de una quebrada, próximo a una pequeńa aguada estacional con indicios de prácticas de molienda. El análisis de las pátinas y superposiciones permite diferenciar dos momentos básicos de ejecución. La asociación original (momento 1) combina elementos de las variedades B1 y B2. Se observa una jerarquía de antropomorfos con aditamentos (patrón A3 y canon C), definida por sus respectivos tamaños y posiciones, junto a no figurativos y camélidos (Figura 7). La vinculación de los camélidos (B1) con los antropomorfos principales (B2) se enmarcaría en el principio de subordinación, debido a su menor tamaño y ubicación en la parte baja del panel. En el momento 2, en este sector bajo preferentemente ocupado por los camélidos, se agregaron nuevas figuras que, en cierta medida, se superpusieron a los motivos originales, restringiendo su visibilidad. Estas nuevas figuras se organizan en torno a un antropomorfo principal del canon $\mathrm{B}$, con indicación del sexo, un objeto tipo vara portado en una mano y una máscara felínica afín a la estilística Aguada (González, 1998). Este personaje está rodeado por motivos más pequeños, antropomorfos del canon $\mathrm{C}$ y no figurativos, posibles representaciones de objetos o emblemas (Figura 7). De este modo, se replicó un aspecto de la temática original (la vinculación jerárquica entre antropomorfos) y se restringió otro, aquel que implicaba la relación con los camélidos. Hasta un punto el principio de subordinación fue mantenido (no todos los camélidos fueron superpuestos) y se sumó el principio de supresión, ya analizado en el caso de Río Guasapampa 2.
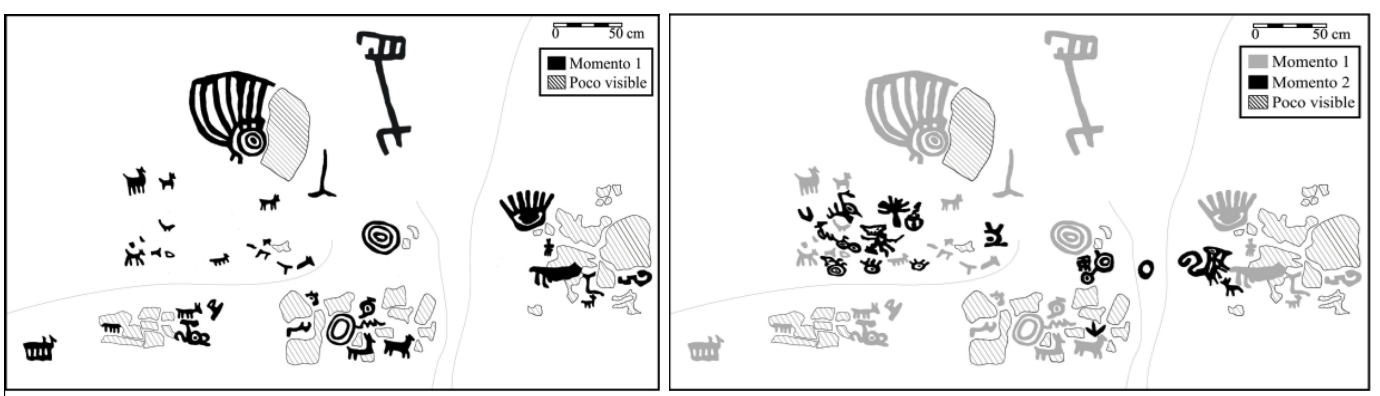

Figura 7: Evolución temática del panel grabado $n^{\circ} 1$ del sitio Los Pilones 2 (área de Lomas Negras), según las diferencias de pátinas.

Figure 7: Thematic evolution of the engraved panel $n^{\circ} 1$ of Los Pilones 2 site (area of Lomas Negras), according to differences in patinas. 
El tercer ejemplo corresponde a Cajones del Igno 3, uno de los sitios pequeńos que circundan a Cajones del Igno 1 , y emplazado como aquel junto a una aguada estacional con indicadores de molienda restringidos a una escala doméstica de interacción. Se documentaron tres paneles dentro de un alero, básicamente asignados a la variedad B1, así como un cuarto de la variedad B2 en un paredón cercano. Esta distribución pone de manifiesto, nuevamente, el principio de segregación predominante en el área. Sin embargo, el panel principal del interior del alero $\left(\mathrm{n}^{\circ} 2\right)$ combina motivos de las dos variedades mayoritarias de la modalidad estilística B, lo cual justifica un tratamiento particularizado. En este caso no se determinaron superposiciones, pero sí diferencias de pátinas que permiten distinguir tres momentos básicos de ejecución. La asociación de motivos del momento 1 corresponde a un típico tema de la variedad B1 (y de la modalidad estilística A), comprendiendo tres camélidos precedidos por un antropomorfo A2, de resolución lineal con indicación del sexo. La diferencia viene dada por la presencia de uno de los motivos más distintivos de la variedad B2, un antropomorfo del canon $\mathrm{C}$ (cabeza con tocado radiado) de tamaño relativamente grande y precediendo a la escena, según su orientación de izquierda a derecha establecida por el rumbo que siguen los camélidos (y en tal sentido, imponiendo un vínculo jerárquico o de subordinación; Figura 8). Con posterioridad la "manada" fue acrecentada con la incorporación de siete camélidos (momento 2), y más tarde otros cuatro (momento 3, Figura 8). De este modo, durante la continuidad del uso y ejecución del panel se respetó el tema y especialmente las jerarquías establecidas en el momento 1. En tal sentido, en este tercer ejemplo no se verifica el principio de supresión, pero sí el de subordinación. 

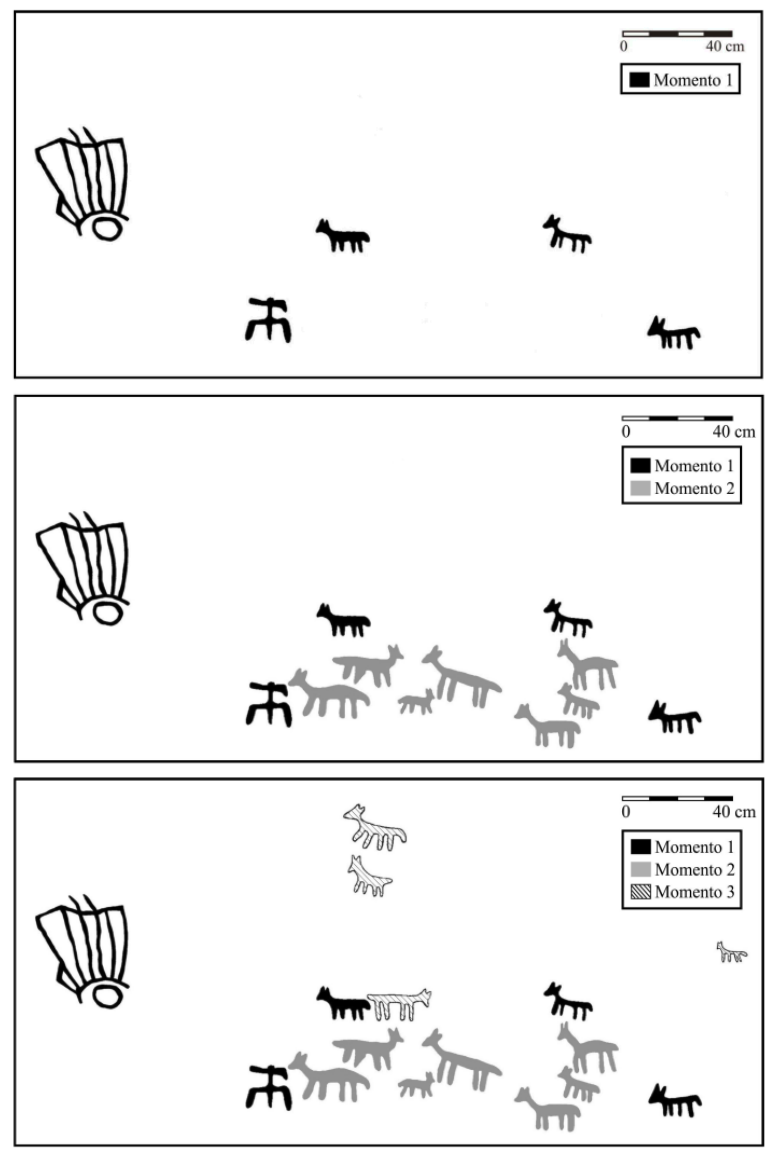

Figura 8: Panel grabado $n^{\circ} 2$ del sitio Cajones del Igno 3 (área de Lomas Negras). Se representa el agregado sucesivo de las figuras de camélidos, según las diferencias de pátinas.

Figure 8: Engraved panel $n^{\circ} 2$ of Cajones del Igno 3 site (area of Lomas Negras). The successive aggregation of camelid figures is represented, according to the differences in patina.

\section{EXCLUSIÓN: ÁREAS DE AGUA DE RAMÓN, TOTORA HUASI Y LAS MAZAS}

El principio que definimos como exclusión se identifica en estas tres áreas del norte del valle de Guasapampa y del piedemonte nororiental de las sierras homónimas (Figura 1), afectando a la variedad B1. Es decir, que sus asociaciones temáticas características (basadas en las imágenes de camélidos) están ausentes por completo, sugiriendo que su ejecución y visibilización no fueron admitidas en estos paisajes. La primera de las áreas, Agua de Ramón, abarca un sector del fondo de valle y las lomadas que constituyen 
el faldeo oriental de las sierras de Pocho. Se distingue por una baja densidad arqueológica (en comparación con Ampiza y Lomas Negras), con presencia de sitios de molienda muy pequeños y dispersos, así como seis paneles con arte rupestre distribuidos en tres sitios. Todos ellos son asignados a la variedad B2, con predominio de los motivos no figurativos y antropomorfos del canon $\mathrm{C}$ (cabezas con tocados), con ausencia total de zoomorfos (excepto una pisada de felino, un tipo de motivo que suele integrar los temas B2 y no los B1).

Este panorama se repite en Totora Huasi, una extensa área ubicada entre Agua de Ramón y la sección sur del valle de Guasapampa (Figura 1), donde se concentran las expresiones de la modalidad estilística A. También aquí se registra una baja densidad de sitios de tamaño pequeño, relacionados con una escala doméstica de participación. Como en Agua de Ramón, y a diferencia de Ampiza y Lomas Negras (y también de Las Mazas), no se identifican áreas de molienda comunitaria. El arte rupestre se distribuye en cinco sitios dispersos, incluyendo siete paneles con imágenes obtenidas por el raspado superficial. En todos los casos son asignados a la variedad B2, con asociaciones de motivos que incluyen no figurativos y/o antropomorfos (Figura 9). Las figuras de camélidos se restringen a sólo dos motivos en posiciones relativamente marginales en sus respectivos paneles.

La baja densidad arqueológica también distingue al área de Las Mazas (Figura 1), excepto sobre el curso de agua principal, el arroyo Las Mazas (de régimen intermitente), donde los sitios presentan una distribución más concentrada. Entre ellos sobresale Las Mazas 1, en torno a un pozo de agua con evidencias de molienda colectiva y ocho paneles con arte rupestre en distintos paredones rocosos y bloques a cielo abierto. De este modo, el contexto del asentamiento se aproxima al de otros sitios de escala comunitaria del área de Lomas Negras como El Cajón 1, Pozo de la Sacha Cabra o Cajones del Igno 1. Tal similitud se refuerza con la presencia exclusiva de asociaciones temáticas asignadas a la variedad B2. Los motivos corresponden a no figurativos y antropomorfos del canon C, en tanto que los camélidos se restringen a una única figura también ubicada en una posición marginal en el panel $n^{\circ} 2$ (Figura 10), como ocurre en Totora Huasi. De este modo, el principio de exclusión de la variedad B1 afecta a todo el espacio que media entre la sección sur de Guasapampa (donde predomina el arte de la modalidad A), y el extremo norte del valle de Guasapampa y occidente de Serrezuela (Figura 1), donde las variedades B1 y B2 coexistieron bajo parámetros con diversos niveles de tensión. 


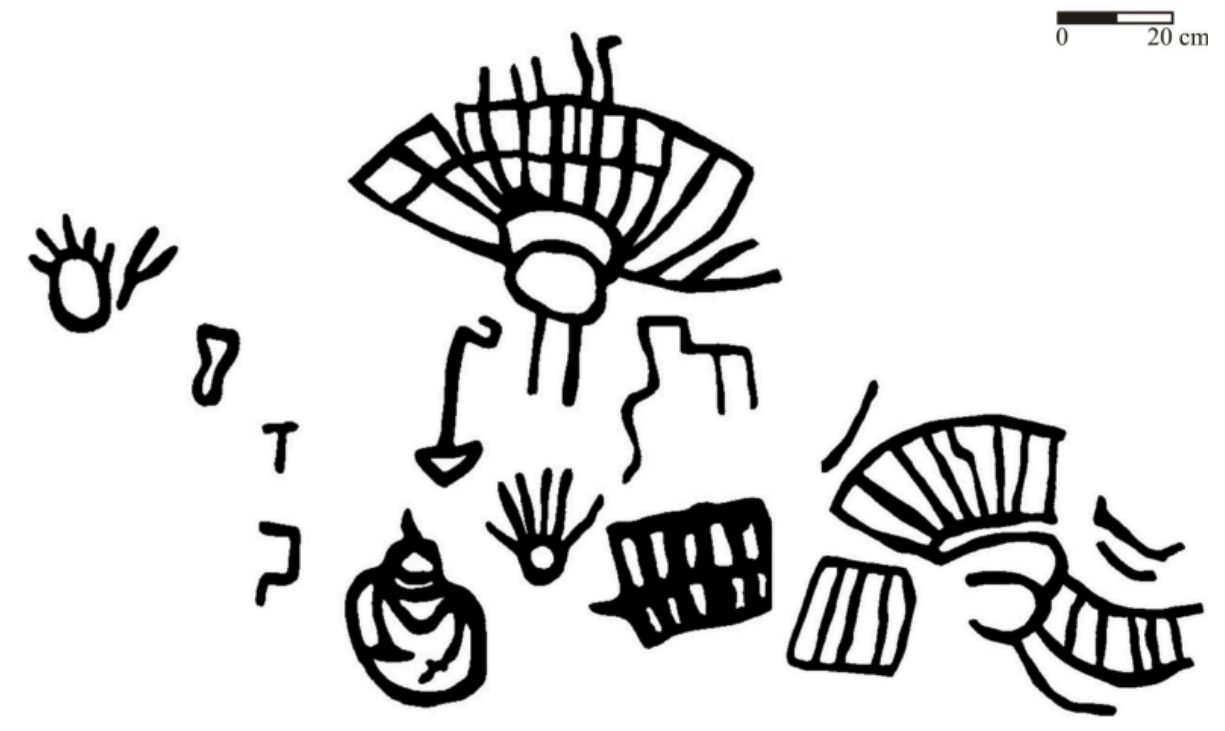

Figura 9: Panel grabado del sitio Quebrada de los Zorros (área de Totora Huasi).

Figure 9: Engraved panel of Quebrada de los Zorros site (area of Totora Huasi).

Arte RUPESTRE DE LA MODALIDAd ESTILÍ́stica B: CONSTRUCCiÓN SOCIAL DE UN PAISAJE DE TENSIÓN

Como mencionamos, el arte rupestre de la modalidad estilística A fue relacionado con la significación de lugares puntuales (refugios rocosos) y con la afirmación de vínculos entre grupos mínimos de pertenencia, unidades familiares, en medio de un paisaje social "abierto", sin límites ni restricciones para la circulación y el acceso a los recursos (Recalde 2009). Este tipo de construcción involucró a espacios discontinuos como el sur del valle de Guasapampa y el oriente de las sierras de Serrezuela (área de Virgen de la Peña; Figura 1). Probablemente, otros entornos con evidencias de ocupación estacional pero sin expresiones de arte rupestre, como el occidente de las sierras de Pocho, también participaban de estas construcciones territoriales "abiertas". 


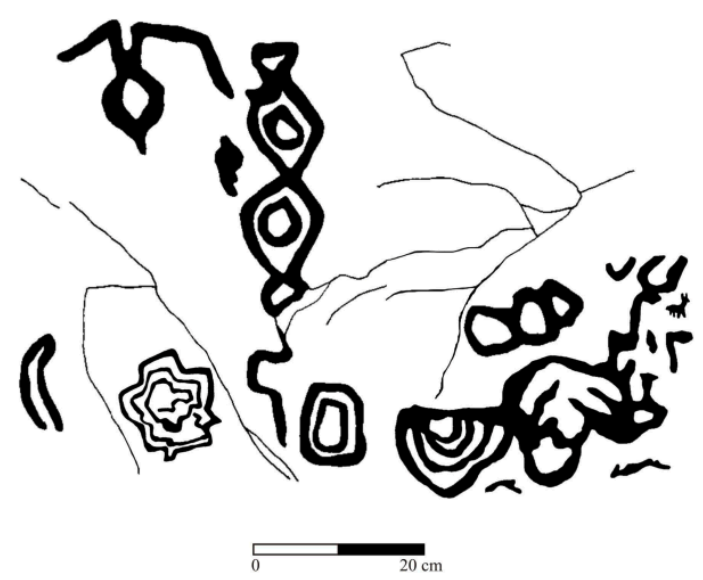

Figura 10: Panel $n^{\circ} 2$ del sitio Las Mazas 1 (área de Las Mazas).

Figure 10: Panel $n^{\circ} 2$ of Las Mazas 1 site (area of Las Mazas).

Las expresiones asignadas a la modalidad estilística B se distribuyen por otros espacios, donde debieron producirse procesos y formas de organización paisajística y territorial diferentes. Éstos habrían conllevado articulaciones asimétricas o jerárquicas entre grupos, con la construcción de un paisaje social "cerrado" (Pastor 2010, Recalde y Pastor 2012). Es decir, con el establecimiento de límites o restricciones para la circulación y el acceso a sitios clave como las aguadas.

Dentro del área de distribución del arte rupestre de la modalidad B, la variedad que definimos como B1 ocupa los sectores con evidencias de una ocupación más intensa del espacio: Ampiza y Lomas Negras (Figura 1). Las vinculaciones de esta variedad con la modalidad estilística $A$, habrían sido de inter-referencia y, a la vez, de oposición. Ambos tipos de expresiones comparten un mismo repertorio iconográfico, las asociaciones temáticas y aún las formas de diseño de los motivos (cánones y patrones constructivos). No obstante, los contextos de producción son disímiles ya que varían los criterios de selección de los soportes, la asociación con los recursos y las técnicas de ejecución de las imágenes. De este modo, las probables significaciones o contenidos semánticos que en el caso de la modalidad A aportaron a la afirmación y reproducción de los vínculos familiares, con el arte B1 se extendieron a un contexto social diferente. Este último habría involucrado mayores posibilidades de visualización, abarcando a colectivos más amplios e inclusivos (tanto a propios como extrańos), y actuando como marcas territoriales que seńalizaban algunos de los hitos de mayor importancia económica y simbólica. 
Sin embargo, la presencia del arte de la variedad B2 en estas mismas áreas, y los vínculos de tensión establecidos con las expresiones B1 (definidos como segregación, y especialmente, como subordinación y supresión), sugieren que aquellas significaciones más propias del ámbito doméstico, pudieron resultar inadecuadas en el proceso de construcción de un paisaje o territorio “cerrado". En tal sentido, el arte B2 recurre a una iconografía y a significados diferentes, seguramente más apropiados en dicho contexto. Los motivos más sobresalientes por su tamaño y posición en los paneles, antropomorfos de cuerpo completo o cabezas con aditamentos como tocados, máscaras y vestimentas, denotan posibles relaciones jerárquicas entre grupos, en tanto referentes de las autoridades o antepasados de quienes se apropiaban de cada entorno particular.

En el caso de Ampiza y Lomas Negras (Figura 1), el principio predominante de segregación indica que ambos tipos de expresiones y significados no fueron admitidos en los mismos lugares específicos. En gran medida, el arte B2 se relaciona con las aguadas principales (El Cajón 1, Cajones del Igno 1, Pozo de la Sacha Cabra), que constituyeron los sitios de mayor importancia "pública" en la microrregión. En ocasiones, estos sitios acogieron la participación de colectivos sociales inclusivos, como lo atestiguan los instrumentos dispuestos para la molienda comunitaria (Pastor 2009, 2010). En otros casos, el principio de segregación pudo resultar insuficiente o inadecuado, y aquellos significados más propios del ámbito doméstico (B1/A) tendieron a ser marginados o eliminados por la imposición de la temática pública y jerárquica del arte B2, a través de los principios de subordinación y supresión (Figuras 6, 7 y 8). La evidencia sugiere que, en algunos casos, los sentidos o "relatos" asociados al arte B2 tendieron a desplazar a las expresiones B1.

En cuanto a Agua de Ramón, Totora Huasi y Las Mazas (Figura 1), el extenso espacio que media entre las áreas de concentración de las representaciones de la modalidad estilística A (sur del valle de Guasapampa) y B (Ampiza y Lomas Negras), registramos el principio de exclusión de las expresiones B1. Asimismo, se aprecia una baja densidad arqueológica indicativa de la limitada intensidad en la ocupación del entorno, claramente contrastante con su riqueza forestal y, en algunos sectores, hídrica. La no admisión del universo simbólico característico de los ámbitos de participación doméstica revela, a nivel del arte rupestre, una máxima oposición con el área vecina del sur de Guasapampa. Adicionalmente, las diferencias en la intensidad de la ocupación definen a este espacio como un medio subexplotado y a la vez restringido para una apropiación "abierta” o ilimitada 
por parte de cualquier grupo. Por el contrario, permitirían caracterizarlo como un paisaje "cerrado" y de tensión (Recalde y Pastor 2012).

En síntesis, durante el Período Prehispánico Tardío el proceso de ocupación de los microambientes áridos de las serranías noroccidentales de Córdoba habría implicado, en ciertos sectores, la construcción de paisajes "abiertos", con posibilidades irrestrictas para la circulación y explotación de los recursos. En tales sectores las prácticas sociales y los significados asociados a la producción del arte rupestre, o bien estuvieron ausentes o conllevaron la adopción de los parámetros definidos para la modalidad estilística A (sur de Guasapampa y Virgen de la Peña). En otros espacios se intentó una construcción distinta, es decir, restrictiva o "cerrada", apelando, en el caso del arte rupestre, a un mismo repertorio iconográfico pero desplegado en otro contexto, que implicaría mayores posibilidades de visualización y demarcación de algunos hitos significativos del paisaje (variedad B1 en Ampiza y Lomas Negras). Sin embargo, en un cierto punto, los contrastes pudieron resultar insuficientes o inadecuados para esta construcción del paisaje y de los vínculos sociales, y el repertorio característico del arte B1 (y A), más apropiado en los contextos de interacción doméstica, tendió a ser marginado e incluso eliminado por las expresiones de la variedad B2. Esta última presenta una distribución más amplia, y puede ser relacionada con el "cerramiento" de un territorio relativamente continuo, abarcando el norte del valle y sierras de Guasapampa y el occidente de las sierras de Serrezuela. Dicho territorio estuvo rodeado por áreas presumiblemente "abiertas", sin sitios con arte rupestre o con manifestaciones de la modalidad estilística A.

Las fuentes históricas de la jurisdicción de "Córdoba del Tucumán” a finales del siglo XVI ofrecen un panorama sobre la organización sociopolítica de los grupos indígenas en el tiempo de la conquista (Bixio y Berberián 1984, Montes 2008, Piana de Cuestas 1992). En tal sentido, se destaca un escenario altamente fragmentado, con una elevada autonomía económica y política de los grupos familiares (linajes y familias extensas). Sin embargo, al mismo tiempo, existen repetidas constancias sobre la integración de dichas unidades o segmentos en estructuras más abarcativas, de escala comunitaria. Tales dependencias e inclusiones se reflejan en las jerarquías de autoridades, con la existencia de "caciques secundarios" obedeciendo a otros "más principales". Las asimetrías pudieron responder a los vínculos de precedencia (por ejemplo entre comunidades "madre" e "hijas"), o como resultado de diversos procesos de negociación. Estos últimos se habrían relacionado con la existencia de derechos territoriales, con el intento de asegurar el acceso a los recursos, y/o con la defensa y colaboración en un contexto de creciente 
conflictividad intergrupal, que incluyó manifestaciones bélicas. En este sentido, son frecuentes las menciones de enfrentamientos intergrupales, en diferentes sectores de la región (Montes 2008, Piana de Cuestas 1992) y en buena medida relacionados con la violación de límites territoriales ${ }^{4}$. Con respecto a la materialidad arqueológica del Período Prehispánico Tardío, sobresalen las escenas de enfrentamientos entre grupos de arqueros en el arte rupestre del Cerro Colorado (sierras del norte de Córdoba, Gardner 1931, Rivero y Recalde 2007) y las señales de violencia (lesiones traumáticas, proyectiles incrustados) en esqueletos humanos (Pastor y Rivero 2010).

En el caso de los paisajes áridos de las serranías septentrionales y noroccidentales de Córdoba, los derechos territoriales y las negociaciones para el acceso a las aguadas o "jagüeyes" pudieron desempeñar un rol protagónico. Las fuentes históricas remarcan la importancia de estas aguadas y la potencialidad de las relaciones de propiedad ejercidas sobre las mismas como fuente de conflictos, establecimiento de alianzas y articulaciones asimétricas entre grupos. Por ejemplo, en la comarca de Nondolma, en el valle de Copacabana, existían dos "jagüeyes" llamados Sacalo y Siquisaca (Montes 2008). En el marco de un proceso judicial de 1598, el cacique Juan Banchucla informó que Sacalo "...era el jagüey de este testigo; y que el jagüey del que bebe Sarbachuctavi, Ybacsiton y Yalama (tres caciques comarcanos con sus indios), se llama Siquisaca; y que cuando se les acava el agua van a beber del xagüey deste testigo llamado Sacalo..." (Piana de Cuesta 1992: 47).

Otra averiguación judicial efectuada en 1590-91 en la zona de Serrezuela, produjo información sobre una conocida aguada que, según las descripciones, podría corresponder a alguno de los sitios arqueológicos investigados en el área (Pastor 2009). Según el cacique Pedro Chucoya Nauan, este "jagüey" se llamaba Chocho Cona Hal y no era un arroyo sino "agua llovediza" que caía de la sierra y estaba represada. El yanacona Gonzalo Animis precisaba que el agua estaba recogida "en unas lozas de peña". Para el vecino feudatario Francisco Pérez de Aragón, Chocho Cona Hal era un “... sitio muy antiguo entre los naturales desta tierra porque los mas pueblos della beben de jagüeyes y a tiempos les falta el agua y acuden a aquel manantial por agua..." (Piana de Cuestas 1992: 46).

Los derechos sobre estos “jagüeyes” principales, capaces de almacenar agua cuando los más pequeños se secaban, y con ello la posibilidad de acoger a grupos relativamente numerosos, colocaría a sus dueños o titulares en una posición ventajosa para la negociación. La capacidad de permitir o negar el acceso a los mismos podría justificar las diferencias jerárquicas 
entre los grupos y sus respectivas autoridades y, en este sentido, las “juntas" y celebraciones colectivas que ocasionalmente tenían lugar en tales sitios fueron reconocidas como ámbitos de afirmación de las diferencias (Pastor, 2009). Así por ejemplo, en un testimonio judicial correspondiente al valle de Punilla, Francisco Calcanchiga informaba que Don Gonçalo Pituninaure era el cacique principal del pueblo de Citon, porque como tal "...mandava y le rrespetaban los indios y quando avia juntas y borracheras entre los indios era el mas rrespetado y le davan lugar de curaca...". Según el testigo Pedro Chicocechipion "...quando se juntan a fiestas lo rrespetaban los yndios por tal y los demas curacas y en los asientos le davan el asiento de curaca y por tal era tenido..." (González Navarro 2005: 63-64).

El arte rupestre de la variedad B2, presente en algunas de las aguadas principales de las serranías noroccidentales, destaca tanto los vínculos simétricos como jerárquicos entre figuras antropomorfas, lo que interpretamos como referencia a los ancestros o autoridades de quienes se apropiaban de cada una de ellas (Figuras 4, 6, 7 y 9). De este modo, durante los eventos de ocupación producidos en contextos colectivos y celebratorios, dicha materialidad pudo desempeñar un rol activo en el establecimiento, asimilación y reproducción de las estructuras y jerarquías sociales. Aun cuando este arte no aborda explícitamente la temática de la violencia, como ocurre con otras modalidades estilísticas en áreas cercanas (v.g. en el Cerro Colorado, Gardner 1931, Rivero y Recalde 2007), habría intervenido activamente en los procesos de negociación y afirmación de las desigualdades, en un escenario de creciente tensión social.

El estudio del arte rupestre en las serranías noroccidentales de Córdoba revela el potencial de estas investigaciones para comprender aspectos de las antiguas construcciones territoriales, así como el establecimiento y negociación de los vínculos sociales en el marco de un proceso histórico definido por la ocupación más intensa y efectiva del espacio, y por el incremento en los niveles de competencia intergrupal.

Agradecimientos: Este trabajo forma parte del proyecto "Condiciones de posibilidad de la reproducción social en sociedades prehispánicas y coloniales tempranas en las Sierras Pampeanas (República Argentina)", dirigido por el Dr. Eduardo Berberián y con un subsidio otorgado por el CONICET (PIP 112-200801-02678). A Andrea Recalde, al editor de la revista y a los tres evaluadores anónimos, por sus agudas observaciones y comentarios que contribuyeron a la mejora de la versión final. Constanza González Navarro facilitó la transcripción del expediente judicial citado en la nota $n^{\circ} 4$. 


\section{NOTAS}

${ }^{1}$ En las últimas décadas la explotación indiscriminada de bloques de tonalita o granito "gris mara" ha destruido fehacientemente numerosos sitios con representaciones rupestres. En los ańos 1970 se llegaron a registrar hasta 60 abrigos rocosos conteniendo este tipo de expresiones (Romero et al., 1973).

2 Según Aschero (2006: 110) la modalidad estilistica comprende patrones de representación, selecciones de emplazamiento y usos semejantes de los soportes, en una trama de relaciones relativamente sincrónica y preservando la posibilidad de incluir estilos diferentes, coexistentes dentro de cada modalidad. De este modo, se flexibiliza el concepto de estilo para abarcar la variabilidad potencial existente en una microrregión, articulando los elementos que se comparten "quebrada a quebrada", en tanto información compartida en un determinado lapso.

${ }^{3}$ La introducción de la tecnología cerámica en las Sierras Centrales de Argentina se produjo en forma paulatina entre ca. 2000 y 1500 AP (Austral y Rocchietti, 1995; Pastor, 2007). De este modo, su presencia constituye un indicador cronológico relativo para los depósitos arqueológicos superficiales o estratificados que contienen este tipo de materiales.

${ }^{4}$ En un proceso judicial donde se buscaban establecer los antiguos límites territoriales entre los indios de Cosquín y los de "la punilla" (actual valle de Punilla), los testigos ofrecieron informaciones sobre los conflictos que se suscitaban al atravesar ciertos linderos (Archivo Histórico de Córdoba, Escribanía 1, Legajo 72, Expediente 2). Según Martín Hamiltocto “...por estos linderos y moxones se dividian las tierras de la Punilla con las tierras de Cosquin de manera que si los unos o los otros... salian a casar no pasaban de los dichos limites y moxones... que si yvan siguiendo alguna casa y asertava a pasar de los dichos linderos la dejavan porque si la seguian pasando adelante abia guerras entre los dichos indios...".

\section{Bibliografía}

Aschero, C. 1996. “¿Adónde van esos guanacos?” En Arqueología. Sólo Patagonia, editado por J. Gómez Otero, pp: 153-162. Centro Nacional Patagónico, Puerto Madryn.

Aschero, C. 2006. "De cazadores y pastores. El arte rupestre de la modalidad Río Punilla en Antofagasta de la Sierra y la cuestión de la complejidad en la Puna meridional Argentina". En Tramas en la Piedra. Producción y usos del arte rupestre, editado por D. Fiore y M. Podestá, pp: 103-140. Sociedad Argentina de Antropología, Buenos Aires.

Austral, A. y A. Rocchietti. 1995. "Arqueología de la pendiente oriental de la sierra de Comechingones". Actas y Memorias del XI Congreso Nacional de Arqueología Argentina, tomo 10, pp: 61-80. San Rafael, Argentina.

Berberián, E. 1984. "Potrero Garay: una entidad sociocultural tardía de la región serrana de la provincia de Córdoba (Rep. Argentina)". Comechingonia 4: 71138.

Bixio, B. y E. Berberián. 1984. "Etnohistoria de la región de Potrero de Garay (Pcia. de Córdoba - Rep. Argentina)". Comechingonia 3: 11-46.

Consens, M. 1986. San Luis. El Arte Rupestre de sus Sierras. Fondo Editorial Sanluiseño, San Luis. 
Criado, F. 1999. "Del terreno al espacio: planeamientos y perspectivas para la arqueología del paisaje”. CAPA 6: 1-63.

Fiore, D. 2009. "La materialidad del arte. Modelos económicos, tecnológicos y cognitivo-visuales". En Perspectivas Actuales en Arqueología Argentina, editado por R. Barberena, K. Borrazzo y L. Borrero, pp: 123-154. CONICET - IMHICIHU, Buenos Aires.

Gallardo, F. 2001. "Arte rupestre y emplazamiento durante el Formativo Temprano en la cuenca del Río Salado (Desierto de Atacama, Norte de Chile)". Boletín del Museo Chileno de Arte Precolombino 8: 88-97.

Gardner, G. 1931. Rock-Painting of North-West Córdoba. Clarendon Press, London.

González, A. 1998. Arte precolombino. Cultura La Aguada. Arqueología y diseños. Filmediciones Valero, Buenos Aires.

González Navarro, C. 2005. Construcción Social del Espacio en las Sierras y Planicies Cordobesas. Tesis para optar al grado de Doctor en Historia, Facultad de Filosofía y Humanidades, Universidad Nacional de Córdoba, Córdoba.

Karlin, U., L. Catalán y R. Coirini. 1994. La Naturaleza y el Hombre en el Chaco Seco. Colección Nuestros Ecosistemas. Proyecto GTZ - Desarrollo Agroforestal en Comunidades Rurales del Noroeste Argentino, Salta.

Montes, A. 2008. Indígenas y Conquistadores de Córdoba. Ediciones Isquitipe, Buenos Aires.

Murra, J. 1965. "Sobre un hallazgo de petroglifos en la sierra de Las Lomas Negras". Notas del Museo Provincial de Ciencias Naturales "Bartolomé Mitre" 6: 3-11.

Pastor, S. 2005. "El sitio Río Yuspe 14 (Pampa de Achala, Córdoba). Perspectivas sobre el uso prehispánico tardío de los ambientes serranos de altura”. Mundo de Antes 4: 87-104.

---- 2007. "Antecedentes de la adopción de la agricultura entre las sociedades prehispánicas de las Sierras Centrales de Argentina (ca. 2500-1000 AP)". Resúmenes extendidos del Segundo Encuentro de Discusión Arqueológica del Nordeste Argentino, pp: 93-98. Paraná, Argentina.

----- 2007-08. "Arroyo Tala Cañada 1 (valle de Salsacate). Espacio doméstico y productivo en el sector central de las Sierras de Córdoba (Argentina) durante el período prehispánico tardío (ca. 1000-300 AP)". Arqueología 14: 41-75. 
2009. "Informe sobre el sitio El Cajón (Serrezuela, Córdoba, Argentina). La ocupación prehispánica de los micro-ambientes áridos próximos a las Salinas Grandes”. Sociedades de Paisajes Áridos y Semi-Áridos 1: 95-114.

----- 2010. "Aproximación inicial a la arqueología del norte de la sierra de Guasapampa y cordón de Serrezuela (Córdoba, Argentina)". Arqueología 16: $151-174$

Pastor, S. y M. Medina. 2005. "El uso prehispánico tardío de los ambientes serranos de altura. Investigaciones arqueológicas en pampa de Achala, de San Luis y de Olaen (Córdoba, Argentina)”. La Zaranda de Ideas 1: 43-58.

Pastor, S.y D. Rivero. 2010. "Violencia interpersonaly demarcaciones territoriales prehispánicas. Contexto del sitio El Alto 5 (Pampa de Achala, Córdoba)”. Comunicación presentada en el XVII Congreso Nacional de Arqueología Argentina. Universidad Nacional de Cuyo, Mendoza.

Piana de Cuestas, J. 1992. Los Indígenas de Córdoba bajo el Régimen Colonial (1570-1620). Dirección General de Publicaciones de la Universidad Nacional de Córdoba, Córdoba.

Piazzini, C. 2006. "Arqueología, espacio y tiempo: una mirada desde Latinoamérica". Arqueología Sudamericana 2 (1): 3-25.

Recalde, A. 2006. "Las representaciones rupestres y su relación con el paisaje. Aproximación a un análisis regional en el sector occidental de las sierras de Córdoba”. Comechingonia 9: 77-90.

----- 2008-09. "Movilidad estacional y representaciones rupestres. Primeras evidencias de ocupaciones estivales vinculadas con la explotación de ambientes chaqueños en las Sierras de Córdoba”. Anales de Arqueología y Etnologia 63-64: 57-80.

----- 2009. "Diferentes entre iguales: el papel del arte rupestre en la reafirmación de identidades en el sur del valle de Guasapampa (Córdoba, Argentina)". Boletín del Museo Chileno de Arte Precolombino 14 (2): 39-56.

----- 2012. "Análisis de la construcción de las figuras equinas en el arte rupestre del valle de Guasapampa como evidencia de una apropiación simbólica del conquistador (Córdoba, Argentina)”. Chungara 44 (1): 69-79.

Recalde, A. y S. Pastor. 2011. "Variabilidad y dispersión de los diseños de camélidos en el occidente de Córdoba (Argentina). Circulación de información, reproducción social y construcciones territoriales prehispánicas”. Comechingonia 15: 93-114. 
2012. "Contextos "públicos” y "privados" para la ejecución del arte rupestre en el valle de Guasapampa (Córdoba, Argentina)". Latin American Antiquity 23 (3): 327-345.

Rivero, D.y A. Recalde. 2007. "El uso del arco en la guerra durante el prehispánico tardío de las Sierras de Córdoba”. Resúmenes ampliados del XVI Congreso Nacional de Arqueología Argentina, tomo I, pp: 73-78. Número Especial de Revista Pacarina, Universidad Nacional de Jujuy.

Rocchietti, A. 2000. "Arte rupestre de las Sierras de Comechingones (Córdoba). Síntesis regional”. En Arte en las rocas: Arte Rupestre, Menhires y Piedras de Colores en Argentina, editado por M. Podestá y M. de Hoyos, pp: 121-128. Sociedad Argentina de Antropología y Asociación de Amigos del Instituto Nacional de Antropología y Pensamiento Latinoamericano, Buenos Aires.

Romero, C. y M. Uanini. 1978. "Los grabados rupestres del sitio Ampiza 1 (Aguas de Ramón, Dpto. Minas, Prov. de Córdoba)". Revista del Instituto de Antropología VI: 111-133.

Romero, C., E. Argüello de Dorsch y M. Uanini. 1973. "El arte rupestre de Córdoba”. Proyecciones 8, Edición especial en homenaje al IV centenario de la fundación de Córdoba.

Troncoso, A. 2005. "Un espacio, tres paisajes, tres sentidos: la configuración rupestre en Chile Central”. Tapa 33: 69-75.

Urquiza, S. 2011. "Arte rupestre de las Sierras del Norte de Córdoba, Argentina". Comechingonia 15: 115-137. 